\title{
Tactile suppression in goal-directed movement
}

\author{
Georgiana Juravle $^{1} \cdot$ Gordon Binsted $^{2} \cdot$ Charles Spence $^{3}$
}

Published online: 28 November 2016

(C) Psychonomic Society, Inc. 2016

\begin{abstract}
Sharing numerous characteristics with suppression in the other senses, tactile suppression is a reliable phenomenon that accompanies movement. By investigating the simplest of movements (e.g., finger flexions), early research tried to explain the origins of the phenomenon in terms of motor command generation together with sensory reafference. Here, we review recent research that has delved into (naturalistic) goal-directed movements. In connection with goal-directed movement, tactile suppression is evident as a decrease in behavioural performance measured shortly prior to, and during, movement execution. It is also reflected in a consistent response bias highlighting the (perceptual) uncertainty of the movement. Goal-directed movement supports the forward model and establishes contextual influences as the defining influences on tactile suppression. Depending on the task at hand, people prioritize a certain percept during movement. Future research, we argue, should focus on studying naturalistic movements, or sequences of movements, that share a common meaning or goal.
\end{abstract}

Keywords Tactile $\cdot$ Suppression $\cdot$ Goal-directed movement . Context

Georgiana Juravle

georgiana.juravle@inserm.fr

1 French National Institute of Health and Medical Research, INSERM, U1028, Lyon Neuroscience Research Center, 16 avenue Doyen Lépine, 69676 Bron, France

2 School of Health \& Exercise Sciences, Faculty of Health \& Social Development, University of British Columbia, Kelowna, Canada

3 Crossmodal Research Laboratory, Department of Experimental Psychology, Oxford University, Oxford, UK
We feel less when we move. This phenomenon, known as tactile suppression, is a reliable consequence of our actions and is easily replicated in experimental settings. In this review, we review recent human research concerned with the processing of tactile information during goal-directed movements of the upper limbs. The literature search was performed with keywords tactile, suppression, or gating, and (goal-directed) movement. Studies were selected that investigated meaningful goal-directed movements toward external objects or locations. Sensory gating for simple movements, such as finger flexions and arm extensions, have been covered in other recent reviews (Chapman \& Tremblay, 2015; Saradjian, 2015). Although we refer to the older research that has used these simple movements, the focus of the present review is on goal-directed movements of the upper limbs. Such movements include, but are not limited to, pointing, reaching, grasping, catching, or throwing; they are always directed toward external objects. These movements were chosen because of their complex visuospatial profile which allows the study of contextual influences on sensory gating. Suppression documented during goal-directed movement shares some characteristics with the suppression that is evident in simple movements. However, it also opens up other avenues when it comes to interpreting the phenomenon of tactile gating. For this reason, here we focus on reviewing those studies that describe the tactile suppression that is related to goal-directed movement, studies which have not yet been brought together in a review.

We start by listing the necessary conditions for sensory suppression to occur during goal-directed movement; we next oppose these findings to the related phenomena within different motor and/or perceptual systems. Tactile suppression idiosyncratic features are next highlighted and a reconsideration of the phenomenon is put forward. We 
close the review by listing the remaining controversies and providing an outlook on the field.

\section{Conditions for tactile suppression}

\section{Sensory information delivered during movement}

The most obvious question that one can ask in the context of tactile suppression is what exactly is it, and why does it occur? This question can be answered from a number of different perspectives, because physiologists, psychologists, and cognitive neuroscientists have all been concerned with the occurrence of the phenomenon. However, the most pervasive demonstration of its existence has been in overt behaviour.

Sensory suppression affects the different senses. The modality of interest here, somatosensation, includes four major submodalities: touch, nociception, itch, and the temperature sense (see Carlson, 2009; Kandel, Schwartz, \& Jessell, 2000; McGlone \& Spence, 2010). Tactile suppression has traditionally been connected to the use of vibratory or electrical stimulation to investigate what is felt during movement. Hence, the focus of this review lies within the first of the somatic senses: exteroceptive touch. ${ }^{1}$ We nevertheless refer to the other somatic modalities in our discussion of tactile suppression.

Early studies were primarily concerned with tactile suppression in response to simple movements. These could be either passive or active movements of the independent digits of the hand, or of the forearm (e.g., Williams \& Chapman, 2000, 2002; Williams, Shenasa, \& Chapman, 1998). The suppression of touch is maximal on the moving limb, though it has been shown to spread to adjacent body parts (e.g., to the shoulder, when measured at the wrist; Williams et al., 1998). In this context, tactile suppression has typically been characterized by a performance decrement in reporting tactile stimulation delivered to a moving body part, as opposed to performance measured while the participant is at rest. Importantly, the tactile suppression that appeared in the case of such simple movements was originally explained as the result of the generation of a motor command, in combination with sensory reafference (Chapman \& Beauchamp, 2006).

Because of the pervasiveness of tactile suppression, researchers subsequently tried to explain the phenomenon by approaching it from the point of view of a different sensory modality - namely, vision. Specifically, the phenomenon of saccadic suppression serves to keep a stable image of the world around us when we rapidly move our eyes (see Burr \& Morrone, 2011, for a review). However, in vision, even

\footnotetext{
${ }^{1}$ Although we not only feel through our skin, but also from within our body. The latter sense, termed interoception, influences our mood and sense of wellbeing (Cameron, 2002; Craig, 2002), as well as our perception of selforientation in space (Vaitl, Mittelstaedt, \& Baisch, 1997; Vaitl, Mittelstaedt, Saborowski, Stark, \& Baisch 2002).
}

though this perceptual decrement during eye movements is clearly evident, there is also proof of enhanced perceptual performance before and after the eye movement has occurred. For example, a number of elegant demonstrations have shown that visual perceptual prowess is improved at the goal of an eye movement (Baldauf \& Deubel, 2008; Collins, Heed, \& Röder, 2010; Deubel \& Schneider, 1996). This finding is nicely accounted for by the purported presence of shared sensorimotor transformations between visual spatial attention and motor preparation (i.e., the premotor theory; see Rizzolatti \& Craighero, 2010; Rizzolatti, Riggio, \& Sheliga, 1994).

\section{Goal-directed movement}

In light of the findings that have emerged from vision, somatosensory researchers hypothesized that detection performance should also be affected during movement execution (i.e., tactile suppression) while being enhanced at the goal location of the movement. However, despite the sensible nature of the hypothesis, the prediction was not found to hold fully in the case of touch. More specifically, experimental findings confirm the premotor theory only with respect to the preparation period of the goal-directed movement. That is, perceptual performance is indeed enhanced while preparing to move, however, this enhancement takes place about a second in advance of the start of the movement (Juravle \& Deubel, 2009; Rorden, Greene, Sasine, \& Baylis, 2002; see also van Ede, van Doren, Damhuis, de Lange, \& Maris, 2015, for a recent replication), with no study to our knowledge having indicated facilitation in the processing of tactile information once the movement has been completed. Note, though, that aside from the complex eye movements used in the above studies, only the simplest of finger flexions or lifting movements have been studied. Finding no perceptual enhancement in the postmovement period could therefore have reflected the choice of simple movements used, where sensory information is not relevant for the action being performed. The sensible next step was then to study tactile suppression (or lack of) during the various phases of meaningful goal-directed movements.

\section{Meaningful goal-directed movement in peripersonal space}

Researchers have switched to the study of those movements having a specific goal. For example, experimental variants of reach-to-grasp (prehension) tasks mirror actions made countless times every day when interacting with our immediate surroundings. Specifically, the participants in one such study had to make a discrimination judgment concerning tactile stimuli that were delivered at various time points during the movement, from preparation, early, mid, and late movement, through to post-movement (Juravle, Deubel, Tan, \& Spence, 2010); the movements were performed under natural viewing conditions, with no visual fixation being imposed on the 
participants. Tactile suppression was seen throughout the execution of the movement. It had a similar profile for both the dominant and the non-dominant hand, but no sign of the expected facilitation in the preparatory period of the movement was obtained. What's more, as soon as the movement ended, there was no evidence of sensory facilitation, but only the absence of sensory suppression (Juravle, Deubel, \& Spence, 2011; Juravle et al., 2010). Consistent with this finding, Colino and colleagues had their participants reach to grasp a target object placed in front of them by using a precision grip (Colino, Buckingham, Cheng, van Donkelaar, \& Binsted, 2014). Tactile sensitivity was measured not only at the index finger reaching to grasp the object but also at the little finger (not involved in the final grasp), at the moving forearm, as well as at the resting forearm. In line with the suppression prediction, sensitivity decreased shortly before the onset of the movement. However, tactile suppression was only present at the forearm of the moving limb, performance remained almost perfect at the index finger (used to grasp). These findings are important because they demonstrate for the first time that tactile information is not gated when it is relevant to the to-be-executed movement of the upper limb.

Note though that earlier electrophysiological studies have demonstrated that the processing of somatosensory information delivered at the ankle joint is enhanced prior to the initiation of a step, when such a step is made under normal gravitational balance (Saradjian, Tremblay, Perrier, Blouin, \& Mouchnino, 2013). Another relevant finding here is that of enhanced processing of tactile stimulation delivered at the lip when this stimulus is concomitantly paired with a meaningful speech stimulus (Thomas, Sink, \& Haggard, 2013). Similarly, the processing of visual information is also affected during goal-directed movement of the hand, as illustrated by findings of a decreased audio-visual fusion illusion in response to increased velocity of the moving limb (Tremblay \& Nguyen, 2010). Future research will need to investigate whether findings such as the reduced gating when the tactile information is relevant to the action being performed (Colino et al., 2014) reflect a lack of suppression at the relevant skin locations for the grasp of the target object. An alternative explanation here, still to be tested, would be that perceptual performance improves as the fingers involved in the grasp approach the target object.

The lack of suppression evident around the time of the grasp could also be caused by the allocation of visual attention during the preparation and execution of the goal-directed movement. We know that when we intend to grasp an object, we will first direct our eyes to the object of interest and then our hand will follow. That is, the execution of an eye movement is connected to the deployment of (overt) visuospatial attention. A recent study (Colino, Lee, \& Binsted, 2016) sought to examine the influence of vision by limiting the availability of visual information specifically at the beginning of the movement, where suppression had previously been shown to peak (Bays, Wolpert, \& Flanagan, 2005; Buckingham, Carey, Colino, DeGrosbois, \& Binsted, 2010; Colino et al., 2014). As expected, results indicated a significant decrement in tactile sensitivity when vision was not available at the initiation of the reach. However, this effect was independent of the time course of tactile suppression. Such a result is unsurprising given that suppression has previously been shown to always make an appearance at the start of the movement, irrespective of whether attention was endogenously directed to the movement relevant effector or not (Juravle et al., 2011).

Furthermore, it is reasonable to have tactile information suppressed at the beginning of a reach, particularly because we do not necessarily need tactile cues at this particular stage of the movement. Researchers need to concentrate specifically on the grasp of the goal object because this is the stage when tactile/haptic feedback is presumably crucial for the successful manipulation of the goal object. For example, by using a reach-to-grasp-and-lift task, Colino and Binsted (2016) recently demonstrated a recovery in suppression at the index finger involved in the grasp, for specifically this later stage of the movement. The finding is important because it underlines the importance of touch for the future grasp of the goal object. $^{2}$ The timing of tactile stimulation delivery is indeed crucial in these goal-directed movement tasks used in the context of sensory suppression, see the critical time window for suppression reviewed in Juravle (2015). For example, a recent study investigated sensory suppression during grasping, pointing in the air, and a control static condition (Debats, Rohde, Glowania, \& Ernst, 2016). The authors manipulated the relevancy of sensory stimulation by delivering it either at a finger involved in the goal-directed action, or not. The findings indicated the existence of even more suppression for the grasping action, contrary to the predicted lack of sensory attenuation in the grasping relevant finger. The reason for such unexpected findings might be particularly the timing of tactile stimulation delivery: In this study, tactile vibratory stimuli were delivered at a (predictable) point in time, that is, always following the onset of hand movement. Because that is the phase where attenuation peaks, future studies need to concentrate specifically on the grasp phase of the movement, where the reduction in sensory attenuation appears to be a sensible outcome.

\footnotetext{
${ }^{2}$ Note, though, that the particular task the participants performed in the study was a composite movement with the reach, short break to grasp, and lift of the target object. Previous findings demonstrating sensory suppression throughout the reach phase and at the grasp of the goal object did not use the final lift off the table surface, and thus have an extra movement following the grasp of the object. For this reason, future research will be needed to clarify whether the results indicating a lack of suppression in the later stage of the movement reflect a true perceptual facilitation at the fingertips, a movement deceleration (or lack of movement in the finger grasping the goal object), the contribution of visual attention, or the combination of (some of) these factors.
} 


\section{The force matching task}

Aside from the reach-to-grasp tasks covered in the present review, a special mention is needed in the case of the rather basic movement involved in the force matching task (Shergill, Bays, Frith, \& Wolpert, 2003): Here, participants are asked to match a reference force delivered to their index finger by either using another finger to press on the finger, or else, a computercontrolled joystick. Due to sensory attenuation, when using their own finger, participants overestimated the force needed to match the initial force, as compared to using the joystick. This task was later modified so that it could resemble an active tapping (Bays et al., 2005): Participants initiated each trial by pressing a force sensor with their right index finger, while their left index finger was kept at rest beneath another force sensor. At the presentation of a go signal, the participants reached toward a third force sensor placed on top of the left force sensor, such that, at the end of the trial, they actively tapped their left finger with their right finger. At variable time delays before or after the active tap (with a maximum of $+300 \mathrm{~ms}$ ), they also received a test tap on the right finger. The task involved rating which of the taps they perceived as being more intense. The results highlighted the existence of sensory suppression, starting in the execution phase of the speeded movement $(-300 \mathrm{~ms})$, with a peak at the contact with the force sensor (the active tap) and ending $100 \mathrm{~ms}$ after contact has been made (Bays et al., 2005). The attenuation evident in the force matching task thus abides by the two crucial rules necessary to define tactile gating: a moving effector (here the finger actively involved in the adjustment of the applied force) and a critical time window to measure perceptual function, which is centered on movement initiation (Juravle, 2015). For example, a recent electroencephalography (EEG) study on the force matching task claims the existence of 'functionally and mechanistically distinct forms of sensory gating', however, perceptual function is measured outside the critical time window for tactile attenuation to occur (see Palmer, Davare, \& Kilner, 2016). Even though the force matching task is dependent on force weight and thus tends to not result in sensory suppression for larger weights (Walsh, Taylor, \& Gandevia, 2011), it is nevertheless a good candidate to study sensory suppression during movement. Active inference has been proposed to account for the trimming of sensory information during action, in that sensory surprise is transferred into motor control representations which are used to minimize sensory prediction errors (Friston, 2005; Friston, Mattout, \& Kilner, 2011). Simulations on the force matching task demonstrated that it was specifically the precision of sensory information that was attenuated during movement (Brown, Adams, Parees, Edwards, \& Friston, 2013). Note, though, that in the force matching task, our prediction errors are formed based not only on feedback from the passive 'receiving' finger, but also from the finger executing the pushing action. Further simulations are needed in order to investigate whether movements toward external objects, such as the goal-directed movements of the upper limbs that we review here, making use of feedback from only the movement effector, similarly abide by the same rules of Bayesian optimal behaviour.

That being said, our current knowledge indicates that tactile suppression dominates from shortly before the movement until its end, with a peak in intensity specifically at the point in time when the movement is initiated (Bays et al., 2005; Buckingham et al., 2010; Colino \& Binsted, 2016). Its occurrence over the execution period of the movement has not only been robustly demonstrated for basic perceptual tasks, addressing the presence or quality of brief touches on the moving or resting effectors (Williams \& Chapman, 2000, 2002; Williams et al., 1998). It has also been shown for more complex perceptual tasks, such as the estimation of force magnitude (Bays et al., 2005; Shergill et al., 2003; Shergill et al., 2013), ticklishness (Blakemore, Frith, \& Wolpert, 1999; Van Doorn, Paton, Howell, \& Hohwy 2015), or the very fine displacement of Braille characters (Ziat, Hayward, Chapman, Ernst, \& Lenay, 2010). Furthermore, tactile suppression has been described in a diversity of motor tasks, ranging from simple fingers/arm movements (Bultitude, Juravle, \& Spence, 2016; Chapman \& Beauchamp, 2006), through goal-directed (bimanual) reaches and reach-to-grasp movements (Buckingham et al., 2010; Colino et al., 2014; Gallace, Zeeden, Röder, \& Spence, 2010; Juravle et al., 2011; Juravle et al., 2010; Juravle, McGlone, \& Spence, 2013), to more naturalistic movements, such as juggling (Juravle \& Spence, 2011), catching and throwing a basketball (Juravle \& Spence, 2012), or even back-bending movements (Van Hulle, Juravle, Spence, Crombez, \& Van Damme, 2013). See Table 1 for a selection of relevant studies that have found tactile suppression, split according to the different motor tasks the participants were asked to perform. For such a range of perceptual and motor tasks related to the occurrence of tactile sensory suppression, the obvious question that arises is, 'How exactly does tactile suppression occur?'

\section{Internal representation in sensation and action}

The sensory information related to movement is processed by different sensory systems that operate in parallel (Kandel et al., 2000). The somatosensory system transforms physical energy into neural signals, and thus generates an internal representation of the world or the current state of the body. Motor processing, on the other hand, is always deemed to begin with an individual's internal representation of the desired goal or result of the movement. That is, in physiological terms, the motor system transforms the neural signals into contractile force in the motor effector muscles. Because of these intimate sensorimotor connections, tactile suppression always needs to be considered in the context of movement. 
Table 1 Examples of relevant studies on tactile suppression that have used either the detection or discrimination of tactile information as a perceptual task, split according to the motor task performed by the participants

\begin{tabular}{|c|c|c|}
\hline Motor task & Perceptual detection & Perceptual discrimination \\
\hline Basic finger or arm flexions & Williams \& Chapman, 2000, 2002; Williams et al., 1998 & Tomassini et al., 2014 \\
\hline Reaches and reach-to-grasp movements & $\begin{array}{l}\text { Buckingham et al., 2010; Colino \& Binsted, 2014, 2016; Colino } \\
\text { et al., } 2014\end{array}$ & $\begin{array}{l}\text { Debats et al., 2016; Juravle et al., 2011, } \\
\text { 2010, } 2013\end{array}$ \\
\hline $\begin{array}{l}\text { Naturalistic movements, including } \\
\text { surface or object exploration }\end{array}$ & Juravle \& Spence, 2011, 2012; Van Hulle et al., 2013 & $\begin{array}{l}\text { Juravle et al., 2013; Rohde, Debats, \& } \\
\text { Ernst, 2015; Ziat et al., } 2010\end{array}$ \\
\hline $\begin{array}{l}\text { Passive movements, imagined or } \\
\text { observed movements }\end{array}$ & $\begin{array}{l}\text { Chapman \& Beauchamp, 2006; Chapman, Bushnell, Miron, } \\
\text { Duncan, \& Lund, 1987; Juravle et al., } 2013\end{array}$ & Juravle et al., 2013; Vastano et al., 2016 \\
\hline
\end{tabular}

Demonstrations of the origin of tactile sensory suppression highlight efferent signals for tactile suppression originating in the primary sensory (SI; London \& Miller, 2013), primary motor (MI; Voss, Bays, Rothwell, \& Wolpert, 2007), and supplementary motor cortices (the SMA; Haggard \& Whitford, 2004; see also more recent approaches from Brown et al. 2015; Conte et al., 2012; Rosenberg-Katz et al., 2012). For example, in a transcranial magnetic stimulation (TMS) study that used inhibitory TMS stimulation over MI, Voss and his colleagues demonstrated an improvement in the perception of self-generated tactile stimuli (i.e., a reduction in tactile suppression; Voss et al., 2007). In another study, the participants had to execute, or restrain themselves from executing, a flexion of the right index finger following an auditory signal (Haggard \& Whitford, 2004). A TMS pulse was delivered over the corresponding index finger representation area of M1 on each trial, producing a finger muscle twitch (test motor-evoked potential; MEP). The participants were instructed to relax and compare this stimulation to a second reference MEP delivered a few seconds later. The results indicated the presence of sensory suppression; that is, participants judged the test MEP as being smaller than the reference MEP on those trials in which they performed the voluntary movement. The interesting fact here is that when a conditioning prepulse was delivered over the SMA, $10 \mathrm{~ms}$ prior to the test MEP, the reported suppression effect was almost abolished. This finding thus points towards the SMA as a trigger for the efferent signal that generates sensory suppression.

So, although the involvement of regions such as the SI/MI might seem intuitive, more anterior premotor and decisionrelated prefrontal brain regions need to be considered as well. This hypothesis concerning the involvement of more anterior brain regions in triggering tactile suppression is plausible given the extant theory that a forward model is at work for every movement that we perform (see Desmurget \& Grafton, 2000; Wolpert, Diedrichsen, \& Flanagan, 2011; Wolpert \& Flanagan, 2001, for reviews). The forward model implies an internal representation of the body and the environmental signals (i.e., a neural forward model, internal to the central nervous system) that are used to predict the sensory consequences of the outgoing motor command (Jordan \& Rumelhart, 1992; Kawato,
1999; Miall \& Wolpert, 1996; Wolpert, Ghahramani, \& Jordan, 1995). The forward model describes the causal link between action and its sensory consequences (Wolpert \& Flanagan, 2001), based on the current state of the body and a copy of the motor command (i.e., efference copy).

One of the principle roles of such an internal model in movement control is to regulate performance by comparing, in real time (i.e., optimal feedback control; Todorov, 2004), the predicted sensory states with the actual sensory states. At the same time, forward models are also used to attenuate movementirrelevant sensory information or to enhance the sensory information that is essential for movement control. Understanding this peculiarity of the forward model is key to understanding sensory suppression. It has thus been suggested that by attenuating the sensory signals resulting from the movement, such a predictive mechanism serves to enhance the salience of external events, or those events that cannot be predicted from the motor command (Bays \& Wolpert, 2007; see also Brown et al., 2013). Although, at present, we do not have a universally valid explanation across movement and perceptual tasks with respect to the purpose of sensory suppression, the forward model does seem to be the best explanatory fit. Note that, to extrapolate the understanding of sensory suppression as studied in the lab to activities of daily life, we might need to consider a cascade of forward models (Pezzulo, Rigoli, \& Friston, 2015; Wolpert \& Flanagan, 2001), as well as the various contextual influences that affect our perceptual systems (e.g., Coen-Cagli, Kohn, \& Schwartz, 2015).

\section{Neural correlates of movement-related tactile processing}

It is sensible to assume that the findings of impaired, as opposed to enhanced, perception of tactile events during movement may reflect the fact that the diverse tactile information processing is carried out by different neural pathways. In those cases where fine tactile discrimination is required, the sensory input is processed in the primary somatosensory cortex (SI) and then relayed to the secondary somatosensory cortex (SII), where the specific nature of the tactile stimulus is assessed (Gallace \& Spence, 2014). This suggested pathway is in line with the results of 
functional magnetic resonance imaging (fMRI) studies that reported a decrease in the blood oxygenation level dependent (BOLD) signal in the parietal operculum (i.e., the region that includes SII) for stimulation delivered to a moving limb (Parkinson et al., 2011). Furthermore, this study also indicated that the decrease in activity in SII was correlated with activity in premotor regions, such as the lateral premotor cortex, the medial cingulate motor cortex (CMA), and the SMA. However, note that $\mathrm{fMRI}$ results are correlational in nature. An empirical demonstration is still lacking concerning how the brain regions that are involved in sensory suppression causally interact with each other, as well as how these interactions are modulated by the experimental manipulations.

The premotor regions have an important role to play in motor planning and the outlining of the motor sequence of the forthcoming goal-directed action. The pre-SMA might be the trigger region for the sensory suppression experienced prior to the start of movement (Haggard \& Whitford, 2004). If it seems reasonable that SII receives inhibitory projections from the premotor cortex, when a decision on the quality of stimulation is needed, it could be speculated that SII, in turn, projects back to the premotor cortex, as highlighted by monkey studies (de Lafuente \& Romo, 2005; Romo, Hernandez, \& Zainos, 2004). Furthermore, given the decisional component to tactile suppression (Colino \& Binsted, 2016; Colino et al., 2014; Juravle \& Spence, 2011, 2012), one needs to consider other frontal brain areas that may be involved in the modulation of what is felt during movement. For example, by using a task that required the participants to discriminate the frequencies of two successive tactile stimuli, human fMRI studies have reported significant activations in the left dorsolateral prefrontal cortex (dIPFC), the anterior CMA, and bilaterally, in the insular cortices (Pleger et al., 2006; see also Fleming et al., 2015). Most importantly, indicating a purposeful modulation of what was felt, this neural activity, seen in the left dlPFC, was particularly sensitive to those trials in which the participants correctly discriminated the tactile stimulus for the trial (Pleger et al., 2006).

Given the potential SII involvement in the gating of somatosensory sensation, what happens in those cases where tactile sensitivity is actually enhanced (Burton \& Sinclair, 2000; Burton, 2001; Nelson, 1996)? A possible resolution to such instances of enhancement in what is felt as opposed to the traditional suppression ${ }^{3}$ would be that in the simple cases where no task is required of the participants (e.g., the brain simply highlights the presence of a sensory event; Juravle

\footnotetext{
${ }^{3}$ Note that a more simplistic way to regard the dissociation between the findings of enhancement and a decrement in what is felt during the motor execution phase is to take into account the timing of the decision: When the 'decision' is made in real time or during movement execution, tactile perception is enhanced. On the other hand, a post hoc judgment of the quality of what is felt will most probably involve some decrement in tactile perception, due to the comparison with the initial prediction on the consequences of movement. Hence, the importance of acknowledging response bias in evaluating sensory suppression during movement.
}

et al., 2016), or those cases where participants detect a tactile stimulus (e.g., Juravle et al., 2011; Juravle \& Spence, 2015), the neuronal processing would instead take place in SI. Such a task, we speculate, wouldn't necessitate evaluation by the SII, and thus it may escape the perceptual decrement that is associated with the ongoing motor prediction. Once the presence of the tactile stimulus has been 'acknowledged' by SI, according to this alternative hypothesis, it could be further directly transmitted to the posterior parietal cortex regions responsible for attention.

Another important region that is thought to represent the timing of our goal-directed actions is the cerebellum. The neocerebellum is involved in the control and planning of voluntary movements while the intermediate cerebellum is involved in regulating the quality of the movement (Gazzaniga, Ivry, \& Mangun, 2002). It has been argued that the cerebellum is a key predictive component in the conceptualization of the internal models of motor control (Desmurget \& Grafton, 2000; Kawato, 1999). For example, the cerebellar cortex is active when a monkey adjusts its grip to accommodate a slippery object (Dugas \& Smith, 1992); Similarly, a patient with cerebellar degeneration exhibits an impaired prediction of the consequences of his movements (Babin-Ratté, Sirigu, Gilles, \& Wing, 1999). In this context, it is important to note that the cerebellum has extensive projections, through the thalamus, to the premotor and prefrontal cortices (Doya, 1999, 2000; Wise, 1985). See Fig. 1 for a hypothetical depiction on what happens to a tactile event arriving at a moving hand.

\section{Contextual factors in tactile suppression}

\section{Agency}

One seminal demonstration of tactile suppression is the fact that you cannot tickle yourself (Weiskrantz, Elliott, \& Darlington, 1971). Participants rate tactile stimulation that is self-produced as not as intense or as ticklish as compared to the same stimulation having an external origin (Blakemore et al., 1999). This process is dependent on sensory predictions, and it is closely related to the sense of agency, or how we attribute the responsibility of our actions.

Audition is perfectly suited to the study of agency in relation to action. For example, it has been shown that the intensity of auditory stimulation is attenuated when sounds are selfgenerated, as compared to when they are generated by other external sources (Weiss, Herwig, \& Schütz-Bosbach, 2011), with sounds being even more strongly attenuated when delivered in social interactive contexts (Weiss et al., 2011). However, our perceptual processing does not differ for sounds that follow actions performed by another actor, or a computer (Weiss et al., 2011). This effect holds even when participants simply believe the sounds to be self-generated, whereas in 


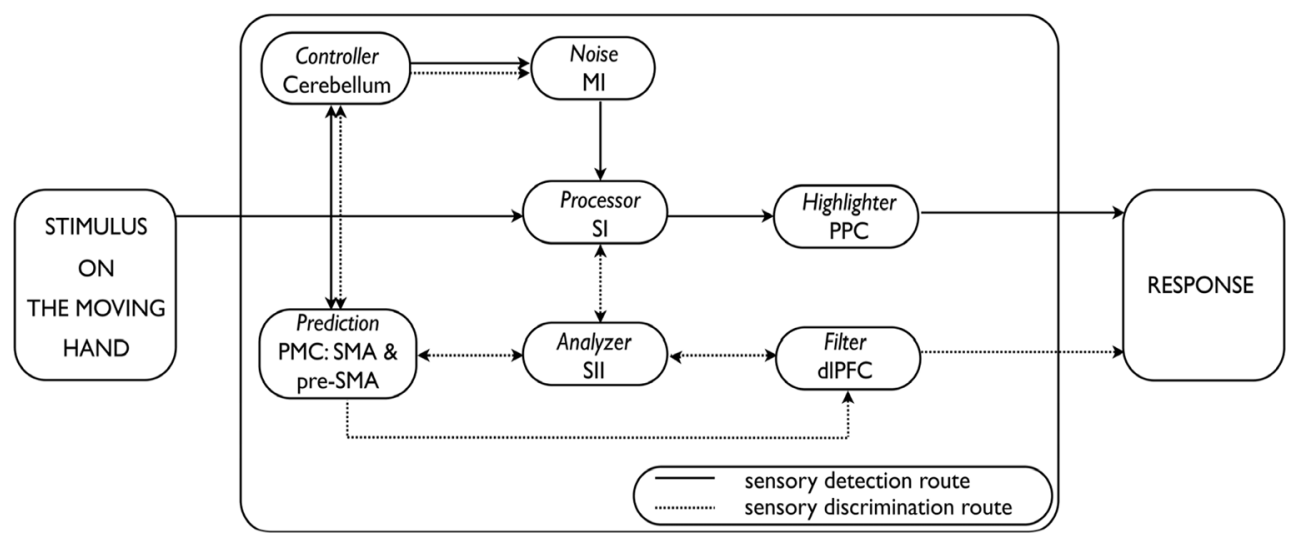

Fig. 1 Model of tactile perception modulations in the moving effector of a goal-directed movement (reproduced with permission from Juravle, 2012). It has been hypothesized that depending on the perceptual task being performed during movement, the final behavioural response can either be enhanced (i.e., by means of attention), or else filtered (i.e., as a result of suppression). For example, a touch arriving at the moving hand is first processed in SI, the Processor; SI also receives Noise from the ongoing motor command and muscle afferents. The tactile information will then be further transmitted to SII, the Analyzer; SII also receives projections from the premotor cortex, related to motor planning and sensory estimates of the movement, the Prediction. If the current perceptual task requires the observer just to detect the presence of a tactile stimulus, then the information processed in $S I$ is further relayed to the posterior

reality they are generated by a computer (Desantis, Weiss, Schütz-Bosbach, \& Waszak, 2012).

Agency judgements are strongly linked to the predictions on the outcome of the action, as specified by the forward model. Empirical demonstrations are available from the patient population. For example, patients with obsessive-compulsive disorder who are characterized by an altered sense of agency seem to exhibit reduced auditory sensory attenuation, as compared to controls (Gentsch, Schütz-Bosbach, Endrass, \& Kathmann, 2012). Similarly, schizophrenic patients exhibiting hallucinations and passivity show no sensory attenuation of self-produced tactile stimulation (Blakemore, Smith, Steel, Johnstone, \& Frith, 2000), an effect explained by an abnormal forward model which impairs selfmonitoring during action (Blakemore, Wolpert, \& Frith, 2002). Similarly, an impaired sense of agency is also responsible for the lack of attenuation of self-produced touch found in patients with functional movement disorders (Macerollo et al., 2015; Pareés et al., 2014).

\section{Response bias}

Recent approaches have seen researchers looking not only at sensitivity in order to characterize tactile suppression but, importantly, also at response bias. Having paradigms consider both sensitivity and response bias is critical because it allows discriminating the perceptual from the decisional component parietal centres, the Highlighter. Thus, the evaluation of the sensory information (as performed by the Analyzer; SII), could be bypassed. However, if a judgment concerning the quality of the incoming stimulation is needed, then the sensory information is passed on to the Analyzer, a structure which is nevertheless 'biased' due to the inherent motor Prediction. Therefore, before making a response, a final stop in the processing of the sensory information could take place again in the premotor/ prefrontal cortex, the Filter. Note that here the cerebellum is depicted as the Controller, given its steady involvement in motor control and training. $\mathrm{PMC}=$ premotor cortex; $\mathrm{SMA}=$ supplementary motor area; $\mathrm{MI}=$ primary motor cortex; $\mathrm{SI}=$ primary somatosensory cortex; $\mathrm{SII}=$ second somatosensory cortex $; \mathrm{PPC}=$ posterior parietal cortex $; \mathrm{dlPFC}=$ dorsolateral prefrontal cortex

of sensory suppression. ${ }^{4}$ That is, any finding of criterion modulations will support a decisional explanation of sensory suppression (see the above hypothetical model), at least with respect to classical signal present/absent experimental designs. ${ }^{5}$

\section{Movement execution}

If we were to look at tactile suppression in the classical sense as a 'mixture' of motor command generation and sensory reafference, then the focus should lie in interpreting sensitivity findings. Any response bias finding in the data is a demonstration of the forward model. For example, we have demonstrated that decrements in sensitivity apparent during the execution phase of a complex motor task are paired with a change in participants' criterion in deciding on the quality of tactile stimulation during movement (Juravle \& Spence, 2011); participants become more conservative in reporting a change in stimulation while moving. Similar conservative shifts over the

\footnotetext{
${ }^{4}$ Note that, historically, researchers have kept sensitivity constant at a certain predefined threshold and then investigated whether any criterion modulation would be evident (e.g., Cardoso-Leite, Mamassian, Schütz-Bosbach, \& Waszak, 2010; Roussel, Hughes, \& Waszak, 2013). No surprise that very seldom did this happen to be the case. However, especially with respect to new paradigms and naturalistic movements, a reasonable approach in order to understand perceptual function seems to be to limit neither sensitivity, nor response bias, by means of an artificial threshold.

${ }^{5}$ Note that it has recently been demonstrated that criterion modulations do not exclusively reflect decisional explanatory factors in the data (e.g., see simulations on the visual Müller-Lyer illusion; Witt, Taylor, Sugovic, \& Wixted, 2015).
} 
period of movement execution have been reported in later studies using reach-to-grasp movements (Colino et al., 2014). Interestingly, more recent work demonstrating a lack of sensory suppression in the finger involved in the grasp as it reaches the target object sheds light on the time course of response bias (or lack of bias). Specifically, participants become unbiased approximately $400 \mathrm{~ms}$ after the movement of their hand has begun (Colino \& Binsted, 2016). Because it takes about $400 \mathrm{~ms}$ to reach the target object, participants have already grasped the target object and (most likely) are involved in the lift movement as they become unbiased. Results such as these therefore suggest that bias might be the direct result of the uncertainty that results from movement itself. Of interest here is a recent investigation we conducted which was aimed at testing whether induced sensorimotor conflict is likely to affect the perception of somatosensory stimuli delivered on a moving limb (Bultitude et al., 2016). Participants performed symmetrical or asymmetrical movements of their right hand while watching a reflection of their left arm in a parasagittal mirror, or the left hand surface of a similarly positioned opaque board. In line with a forward model prediction of sensory modulations during movement, tactile sensitivity was lower during symmetrical movements performed under mirror visual feedback. However, we found no response bias modulation, a result that suggests that the anomalous sensations previously reported in the pain literature in connection to movement would reflect only a change in response bias, rather than real sensitivity to tactile stimulation.

\section{Movement preparation}

Modulations of response criteria during movement are sensible and can easily be attributed to the movement-related uncertainty. The interesting bit, however, is the response bias behaviour observed in the absence of movement, particularly while preparing to perform a goal-directed movement. For example, we were interested in the preparation period of a naturalistic movement (Juravle \& Spence, 2012). Our findings demonstrate that sensitivity declines while preparing to throw, but not while preparing to catch, a ball. These findings seem to suggest that self-initiated actions are prone to sensory suppression, more so than reflexive ones. Alternatively, the same finding could be considered with respect to the sensory information relevant for the task at hand: Throwing a ball could rely more on vector planning and thus be guided by vision, whereas catching a ball could instead rely on joint-based motor commands, and thus be primarily ruled by proprioception (Sober \& Sabes, 2003). Importantly though, participants changed their criterion while preparing the self-/externally generated actions: That is, even before they initiated their movement, when their movement effector was still in a resting state, participants were less likely to report a change in the tactile stimulus occurring at their wrist. Additionally, it seems that we are more likely to experience sensory events related to movement when we adopt the expected body posture for executing the particular movement as well as becoming more conservative in reporting changes in tactile stimulation (on our wrist) when we simply observe an action (Juravle \& Spence, 2012; see also Vastano et al., 2016, for a recent behavioural demonstration, and Voisin et al., 2011, for an electrophysiological investigation). These results are thus important because they suggest that sensory suppression could be triggered in decision-related (i.e., frontal) brain areas, in the absence of movement (Juravle \& Spence, 2012).

\section{Imagining a movement}

It is also sensible to question whether only imagining a movement will result in tactile suppression. For example, the magnitude of the startle response, an index of motor preparation, is comparable across the preparation of simple key presses, and their mere imagination or observation (Maslovat, Chua, \& Hodges, 2013). Similarly, imagined stimuli seem to be treated in the same way as other direct sensory stimulation because they engage in multisensory interactions with those stimuli that are perceived directly (Berger \& Ehrsson, 2013). Furthermore, brain activity during real and imagined hand movements seems to concentrate in related brain networks, as compared to rest (Gerardin et al., 2000; though see Deiber et al., 1998; see also Jeannerod \& Frak, 1999, for a review). The relatedness of brain regions for real and imagined movements seems to be valid specifically in the case of executing or observing biological movements executed by a human actor (Kilner, Hamilton, \& Blakemore, 2007; Kilner, Paulignan, \& Blakemore, 2003). Having the perception of tactile events attenuated during the mere imagination of movement would bring an additional demonstration of the importance of contextual factors in finding an explanation for tactile sensory suppression.

\section{Exceptions to tactile suppression}

\section{Type (or lack) of perceptual task during goal-directed movement}

\section{Reaction times}

As described above, judgments related to the quality, intensity, or force of tactile stimulation under conditions of movement all seem to suffer from the pervasive phenomenon of tactile suppression. On the other hand, a touch on the movement effector is processed differently in those tasks measuring the speed of a participant's reaction to sensory events. Note that the speed of reaction is one of the leading behavioural measures in cognitive science (see Posner, 1978, for a review; though see also Watt, 1991). 
In one of our earlier studies using reach-to-grasp movements, tactile stimulation was delivered with low, even, or high probability to our participants' moving or resting effectors (Juravle et al., 2011). The participants knew in advance, by means of experimental instructions, where the stimulation was most likely to come from during a given block of trials. Moreover, stimulation was delivered either while preparing the movement, while executing the reaching movement, or in the post-grasp period. The results consistently indicated that participants detected the tactile stimulus more rapidly when it was delivered during the movement execution period. Similarly, in a recent study concerned with naturalistic movements (i.e., catching or throwing a ball; Juravle \& Spence, 2015), participants detected the tactile stimulus more rapidly when this was delivered while moving, as opposed to while preparing to catch the ball, and the period after the movement execution. Interestingly, participants appeared to respond more rapidly to tactile stimulation when throwing, thus indicating that objects entering peripersonal space have an attentional-capture-like effect on our processing of tactile information.

\section{Electroencephalography}

Further, the enhancement of what is felt during movement is also evident at the neural level. For example, in another study, we recorded the continuous EEG while our participants reached and grasped a centrally located object on the table in front of them (Juravle et al., 2016). During the various stages of the goal-directed movement, the participants received tactile probes, visual probes, or no sensory probe whatsoever; they were simply told to perform the movement and to pay no particular attention to the occurrence of sensory events. We were interested in how the brain processed these sensory events across the various periods of the movement where they were delivered. The results indicated that the ERPs elicited by the sensory events, both tactile (the N140) and visual (the N100), occurring during movement execution were significantly enhanced, relative to those ERPs elicited in the preparatory and post-movement phases. This finding is consistent with a supramodal mechanism acting on perception during movement and is in line with the previous behavioural findings documenting faster responses during movement (Juravle et al., 2011; Juravle \& Spence, 2015). Relevant here is a study that investigated somatosensory ERPs prior to and following a moderate aerobic exercise (Popovich \& Staines, 2015). Participants received tactile stimuli to two digits of their hand, but were instructed to report those delivered to only one of their digits. Even though the ERPs were not recorded during movement, the results indicated that the N140 ERP was enhanced for the non-attended stimuli, irrespective of whether they were delivered before or after the aerobic exercise. Similar results of increased somatosensory ERP amplitudes have also been earlier reported for much simpler movements of hand clenching or gripping (Lee \& White, 1974).

It appears that the later somatosensory-evoked potentials recorded during goal-directed movement remain unaffected by sensory suppression (Juravle et al., 2016; Lee \& White, 1974). On the other hand, the earlier somatosensory evoked potentials (within the first $100 \mathrm{~ms}$ poststimulus onset) were nevertheless attenuated during movement, with the size of attenuation of early ERPs positively correlated to the size of enhancement in the late N140 (Nakata, Sakamoto, Yumoto, \& Kakigi, 2011). Results such as these determined the authors to discuss possible different generators in the brain for the two outcomes of perceptual attenuation and perceptual enhancement, related to movement (Kida, Nishihira, Wasaka, Sakajiri, \& Tazoe, 2004; Kida, Wasaka, Nakata, Akatsuka, \& Kakigi, 2006; Nakata, Inui, Wasaka, Nishihira, \& Kakigi, 2003). Additionally, the attenuation of somatosensory ERPs is influenced by the context of the movement that participants are subjected to. For example, Wasaka and colleagues had their participants perform a visuomotor tracking task of a line that was the depiction of their grip force on the pencil (Wasaka, Kida, \& Kakigi, 2012). Participants received median nerve stimulation. Results indicated that even though the physical force generated during the generation and the relaxation phases of the grip was virtually the same, the somatosensory ERPs in connection to stimulation delivered during force generation were significantly attenuated as compared to those delivered during force relaxation. These findings suggest a contextual influence on somatosensory processing depending on demands of the motor task.

The processing of tactile information during goal-directed movement thus seems to be unaffected by tactile suppression when no behavioural task is required of participants (Juravle et al., 2016), or when they have to make speeded responses to sensory stimulation (Juravle et al., 2011; Juravle \& Spence, 2015). Context thus seems to play a crucial role in the generation of tactile sensory suppression. Context is defined here with particular reference to the requirements of the motor task the participants are required to perform.

\section{Pantomimed movements}

Furthermore, other demonstrations of context-dependency of movement translated to perception come from investigations into real reach-to-grasp movements as opposed to pantomime grasping. In the latter, participants perform the reach next to the target object, where they mimic grasping an (imaginary) object (Goodale, Jakobson, \& Keillor, 1994). If perceptual performance deteriorates during movement for the real reach-to-grasp movement, as an indicator of tactile suppression, it is, on the other hand, not altered for the pantomimed movement (Colino \& Binsted, 2014). This effect must reflect the lack of variability in hand preshaping for the actual grasp, 
as opposed to the pantomimed one, indicating that the forward model prediction is likely to filter out any sensory consequence related to one's movement.

\section{Active touch}

How can we have tactile information gated when for some specific movements it will always get enhanced? The easiest example to consider is active touch (Klatzky, Lederman, \& Metzger, 1985; Lederman \& Klatzky, 2009). That is, movements we make with the purpose of gaining tactile information about a surface tend to enhance the perceptual sensation. This has been demonstrated for different types of tactile information, when paired with active movements.

We have contrasted the execution of simple reaches to that of exploratory movements and measured tactile performance (Juravle et al., 2013). Specifically, tactile sensitivity was measured at the wrist and, as expected, the results revealed a decrement in sensitivity during movement (Juravle et al., 2011, 2010). However, we also had an additional measure of tactile sensation - on some trials, our participants also judged whether the materials covering the surface of the table were the same, or different. The two tactile tasks could be performed either in isolation or else together, and during both active and passive movement. In support of the enhanced feeling known to result from active touch, we found that performance in the table surface discrimination task was significantly improved when performed alone, during active movement, and, importantly, during exploration (Juravle et al., 2013). However, even though performance was clearly affected by the dual-task used, tactile suppression measured at the wrist occurred independently of the perceptual enhancement documented during the surface discrimination task (Juravle et al., 2013).

\section{Affective touch}

A distinction has been made between discriminative and emotional touch (McGlone, Vallbo, Olausson, Loken, \& Wessberg, 2007). ${ }^{6}$ It appears that the discriminative touch that is highly likely to be affected by sensory suppression corresponds to sensing, whereas pleasurable touch relates to feeling (McGlone, Wessberg, \& Olausson, 2014). Interestingly, sexual intercourse (involving movement and tactile sensation) also results in enhancement of what is felt, as opposed to the expected suppression of tactile information during not pleasurable movement. A hormonal-mediated refractory period appearing following orgasm and characterized by

\footnotetext{
${ }^{6}$ Interestingly, to the best of our knowledge, no behavioural studies have looked at tactile suppression in connection to affective processes; it nevertheless seems that both early somatosensory ERPs (Montoya \& Sitges, 2006) and visual ERPs (Hughes, 2015) are reduced in response to fear-related visual stimulation.
}

hypersensitivity and aversiveness to further stimulation seems to affect tactile sensitivity in both sexes (Humphries \& Cioe, 2009; Masters \& Johnson, 1966; see also Gallace \& Spence, 2014). The natural question that arises is whether affective touch is gated during purposeful movement in a similar manner as it is during the discriminatory touches. Although we are not aware of any such direct demonstration of affective tactile gating, it seems that we do experience other people's skin to be softer than ours, an effect termed 'the social softness illusion' (Gentsch, Panagiotopoulou, \& Fotopoulou, 2015). Outcomes such as these are likely due to the different types of tactile afferent information known to be responsible for the resulting affective versus discriminative touch (McGlone et al., 2012). The different afferent pathway for relaying painful and thermal information could also be implicated in those reported cases of a lack of suppression for painful (Helmchen, Mohr, Erdmann, Binkofski, \& Büchel, 2006), as well as thermal stimuli (Van Doorn, Richardson, Wuillemin, \& Symmons, 2005; see also Juravle, 2015, for a commentary).

Findings such as these, documenting a lack of sensory suppression, could provide the avenue for approaching the functional purpose of tactile sensory suppression during goal-directed movement. Taken together, it would thus appear that the contextual tactile stimulation that carries meaning for our current activities escapes the influence of tactile sensory suppression. These cases where suppression fails to make an appearance are referred to as tactile enhancement (Juravle et al., 2016; Juravle \& Spence, 2015). A summary of relevant studies with the outcome of either tactile suppression or tactile enhancement as a function of the dependent variable utilized in the studies is presented in Table 2.

\section{Suppression across sensory modalities and motor systems}

Perhaps the best way to understand tactile suppression is to look at potential examples of suppression in the other senses. Take, for example, the physiological phenomenon of having images suppressed during very fast eye movements that we execute (i.e., saccadic suppression; Bridgeman, Hendry, \& Stark, 1975; Morrone, Ross, \& Burr, 2005). Similarly, muscle sense is attenuated during movement and seems to abide to the velocity rule we also encounter for tactile suppression (Collins, Cameron, Gillard, \& Prochazka, 1998). Furthermore, underlining the importance of the sense of agency for goal-directed action, electrophysiological studies of auditory suppression indicate that we suppress 
Table 2 Examples of relevant studies on tactile suppression and tactile enhancement, split according to the main dependent variables used

\begin{tabular}{|c|c|c|}
\hline Dependent variable & Tactile suppression & Tactile enhancement \\
\hline Reaction times & & $\begin{array}{l}\text { Juravle et al., 2011; Juravle \& Spence, } \\
\quad 2015\end{array}$ \\
\hline Percentage of correct responses & $\begin{array}{l}\text { Buckingham et al., 2010; Williams \& Chapman, 2000, 2002; } \\
\text { Williams et al., } 1998\end{array}$ & $\begin{array}{l}\text { Farnè, Brozzoli, Senna, \& Pavani, 2015; } \\
\quad \text { Voudouris \& Fiehler, } 2015\end{array}$ \\
\hline $\begin{array}{l}\text { Signal detection theory } \\
\text { measures (d' or response } \\
\text { criteria) }\end{array}$ & $\begin{array}{l}\text { Bultitude et al., 2016; Chapman \& Beauchamp, 2006; Colino } \\
\quad \text { \& Binsted, 2014; Colino et al., 2014; Juravle \& Spence, 2011, } 2012\end{array}$ & Colino \& Binsted, 2016 \\
\hline Neural activity & $\begin{array}{l}\text { Nakata et al., 2003, 2011; Parkinson et al., 2011; Rossini et al., 1996; } \\
\text { Rossini et al., 1999; Shergill et al., 2013; Voisin et al., 2011; } \\
\text { Wasaka et al., 2012 }\end{array}$ & $\begin{array}{l}\text { Juravle et al., 2016; Lee \& White, 1974; } \\
\text { Mouchnino et al., 2015; Popovich \& } \\
\text { Staines, } 2015\end{array}$ \\
\hline
\end{tabular}

sounds resulting from our own actions (Kühn et al., 2011; Timm, Sanmiguel, Keil, Schröger, \& Schönwiesner, 2014). It would be interesting to assess the contribution of tongue or mouth movements involved in the generation of oral-somatosensory sensations.

Relatedly, it would be interesting to investigate if similarly to the existing results of increased tactile suppression occurring for faster movements, we would eventually taste or perceive less of the food we eat when we eat it rapidly. Indeed, eating our food with faster speed seems to result in reduced oral sensation (de Graaf, 2012). Paralleling the sensory suppression found during limb movements, it appears that we are worse at detecting forces applied to a central incisor tooth during jaw closing movements, as compared to forces delivered during a static jaw condition (Sowman, Brinkworth, \& Türker, 2010). It is still needed to investigate whether force detection improves during complex masticatory movements, relative to the simple jaw closing. On the other hand, of course taste is the ideal candidate modality for enhancement in what is being tasted, as opposed to suppression: For example, active tongue and mouth movements result in an enhanced monosodium glutamate savoury taste, but not other taste stimuli (Green \& Nachtigal, 2012).

Suppression seems to be sharing traits across the senses. Given that suppression is so pervasive, care needs to be taken so as not to interpret each occurrence as a new phenomenon (e.g., see results on time compression during simple movements; Tomassini, Gori, Baud-Bovy, Sandini, \& Morrone, 2014). It has been suggested that the documented time compression and the (intensity-based) suppression of tactile sensation might reflect the same brain mechanism at work during the execution of movement (Juravle, 2015). Thus, future research needs to integrate existing findings and characterize suppression across physical dimensions. Importantly, one cannot consider the sensory attenuation of perceptual information in pure isolation: Sensory attenuation accompanies a certain motor system (e.g., the eye, the hand, the foot, the tongue). In order for suppression to occur, we need a meaningful pairing between motor and perceptual systems (Blouin, Saradjian, Lebar, Guillaume, \& Mouchnino, 2014). For example, auditory stimuli are not suppressed during saccades (Harris \& Lieberman, 1996), or while juggling (Juravle \& Spence, 2011), although their processing seems to be significantly altered when their occurrence coincides with the initiation of speeded reaches (Manson, Wong, \& Tremblay, 2012).

\section{A reconsideration of tactile suppression}

We need to integrate known facts on sensory suppression to describe how the tactual sensation is being suppressed or enhanced during movement. A prime condition for sensory suppression is agency. Further, depending on the task, we will prioritize a certain percept or feeling over another, a process that is referred to as a contextual influence. Such a prioritizing process makes capacity available for the preferential treatment of other sensory information, aside from touch, during movement (e.g., visual information; Brozzoli, Pavani, Urquizar, Cardinali, \& Farne, 2009). Additionally, tactile suppression is governed by the forward model during movement (Jordan \& Rumelhart, 1992; Kawato, 1999; Miall \& Wolpert, 1996; Wolpert et al., 1995). However, with respect to goal-directed movements it is necessary to accept a cascade of forward models working together to accomplish the planned goal (Pezzulo et al., 2015; Wolpert \& Flanagan, 2001). For example, one way to approach sensory suppression in future research is by looking at 'making breakfast' over investigating the simple 'reaching for the cup' action.

The key message as far as future research is concerned is thus to approach perception by identifying snippets of daily 
naturalistic activities clustered together in terms of their meaning. ${ }^{7}$ This would allow a solid start in understanding or even controlling the perceptual novelty or surprise. The most important missing piece of the puzzle is still why sensory efficiency would diminish during movement. In addition, there seems only to be question marks with regard to its usefulness. One working hypothesis to still explore is that by such attenuation the 'scene' (i.e., the body environment) is prepared/made ready/transformed into the scene for something else. For example, nature is rife with examples of processes which were once thought of as irrelevant, and which have proved to be meaningful (e.g., the aplysia biting or swallowing muscles; Lu, Mcmanus, Cullins, \& Chiel, 2015). Research is still needed in order to pinpoint what exactly this missing puzzle is with respect to the movement consequences seen in the tactile domain.

Alternatively, a potential solution to the existence of tactile sensory suppression could be given by identifying those tasks, or situations, which are improved during movement execution (e.g., a meaningful example would be an enhancement in visual acuity in extrapersonal space during naturalistic goaldirected movements). Additionally, another interesting path to approach sensory suppression is to investigate whether by distorting certain aspects of movement we could then enhance perception. After all, when slowing down our movement, tactile sensory suppression apparently disappears (CybulskaKlosowicz, Meftah, Raby, Lemieux, \& Chapman, 2011).

It is thus time to reconsider the classical explanation of tactile suppression (see Chapman \& Tremblay, 2015; Saradjian, 2015, for recent reviews). Early investigations have concentrated on very simple movements and have brought valuable insights concerning the nature of tactile suppression, while more recent research has investigated complex goaldirected movements, such as reach-to-grasp movements, back movements, or juggling, to name a few. While many of the findings are consistent, others necessitate new directions for interpretation. It seems that there are certain features of tactile suppression that are shared between the simplest of finger flexions and reaching with the arm. In such cases, suppression acts like a filter to remove irrelevant sensory information. However, there are those cases where sensation is enhanced during movement or as a result of the movement, as well as those cases where the context in which the movement is executed influences the resulting sensation. For such cases, we could eventually prioritize in our own perceptual process only certain characteristics of sensation resulting from movement, depending on context, agency, and our own criterion with

\footnotetext{
${ }^{7}$ Even just considering the current explosion in wearable technology (e.g., Blum, Frissen, \& Cooperstock, 2015), but also clothing and other accessories involving vibratory signals or messages (Chan, Estève, Fourniols, Escriba, \& Campo, 2012; Gallace \& Spence, 2014; Gomez \& Harrison, 2014), tactile suppression needs to be taken into account (see Juravle \& Spence, 2015, for a discussion).
}

respect to the entire activity we find ourselves performing. The key to understanding what gets highlighted is meaning That is, the cluster of independent actions performed in succession need to be grouped by meaning, or share a common goal.

\section{Conclusions and outlook}

As this review has hopefully made clear, tactile suppression is a pervasive phenomenon that appears in connection with meaningful goal-directed movement and which is liable to variable influences, the most notable of which being context. Certain types of movement escape the detrimental influence of sensory suppression; amongst those we list pantomimed movements and active and affective touch. There are shared characteristics between suppression in touch and the other senses; a meaningful pairing between motor and sensory systems is needed for sensory suppression. On closing, just consider the likelihood of performing the same finger flexion about 300 times over the course of a regular day, or even over the course of an hour, as in a typical psychological study. Eventually, one can indeed perform a significant number of reach-to-grasp movements, if working at an assembly line, say (see Crossman, 1959, for a model opposing skill aquisition and time spent at an assembly line). However, the prospect of such a high number of reach-to-grasp movements is highly unlikely in a naturalistic setting. It is much more likely that over the time-course of a regular day we will step on a bunch of slippery leaves, hug a friend, adjust our grip on an unexpectedly hot coffee cup, or simply put up the window blinds in our office. Future research needs to concentrate on naturalistic movements and investigate the underlying perception-action relationship in a necessarily dynamic environment. It is thus crucial for future research to investigate movements with a goal, so that we can extrapolate findings to real life situations. Importantly, in order to maximize the ecological validity of our studies, we need carefully thought-out experiments that will allow us to welcome uncertainty in to the lab. That is, future research needs to also consider the real day-to-day challenges to the tactile modality.

Acknowledgements G. B. is supported by the Natural Sciences and Engineering Council of Canada. C.S. would like to acknowledge the AHRC Rethinking the Senses Grant (AH/L007053/1).

\section{References}

Babin-Ratté, S., Sirigu, A., Gilles, M., \& Wing, A. (1999). Impaired anticipatory finger grip-force adjustments in a case of cerebellar degeneration. Experimental Brain Research, 128(1/2), 81-85. doi:10.1007/s002210050821 
Baldauf, D., \& Deubel, H. (2008). Properties of attentional selection during the preparation of sequential saccades. Experimental Brain Research, 184(3), 411-425. doi:10.1007/s00221-007-1114-x

Bays, P. M., \& Wolpert, D. M. (2007). Computational principles of sensorimotor control that minimize uncertainty and variability. Journal of Physiology, 578(2), 387-396. doi:10.1113/jphysiol.2006.120121

Bays, P. M., Wolpert, D. M., \& Flanagan, J. R. (2005). Perception of the consequences of self-action is temporally tuned and event driven. Current Biology, 15(12), 1125-1128. doi:10.1016/j. cub.2005.05.023

Berger, C. C., \& Ehrsson, H. H. (2013). Mental imagery changes multisensory perception. Current Biology, 23(14), 1367-1372. doi:10.1016/j.cub.2013.06.012

Blakemore, S.-J., Frith, C. D., \& Wolpert, D. M. (1999). Spatio-temporal prediction modulates the perception of self-produced stimuli. Journal of Cognitive Neuroscience, 11(5), 551-559. doi:10.1162 /089892999563607

Blakemore, S.-J., Smith, J., Steel, R., Johnstone, C. E., \& Frith, C. D. (2000). The perception of self-produced sensory stimuli in patients with auditory hallucinations and passivity experiences: Evidence for a breakdown in self-monitoring. Psychological Medicine, 30(5), 1131-1139.

Blakemore, S.-J., Wolpert, D. M., \& Frith, C. D. (2002). Abnormalities in the awareness of action. Trends in Cognitive Sciences, 6(6), 237242. doi:10.1016/S1364-6613(02)01907-1

Blouin, J., Saradjian, A. H., Lebar, N., Guillaume, A., \& Mouchnino, L. (2014). Opposed optimal strategies of weighting somatosensory inputs for planning reaching movements towards visual and proprioceptive targets. Journal of Neurophysiology, 112, 2290-2301. doi: $10.1152 / j n .00857 .2013$

Blum, J. R., Frissen, I., \& Cooperstock, J. R. (2015). Improving haptic feedback on wearable devices through accelerometer measurements. Proceedings of the 28th Annual ACM Symposium on User Interface Software \& Technology. doi:10.1145/2807442.2807474

Bridgeman, B., Hendry, D., \& Stark, L. (1975). Failure to detect displacement of the visual world during saccadic eye movements. Vision Research, 15(6), 719-722. doi:10.1016/0042-6989(75)90290-4

Brown, H., Adams, R. A., Parees, I., Edwards, M., \& Friston, K. (2013). Active inference, sensory attenuation and illusions. Cognitive Processing, 14(4), 411-427. doi:10.1007/s10339-013-0571-3

Brown, K. E., Ferris, J. K., Amanian, M. A., Staines, W. R., \& Boyd, L. A. (2015). Task-relevancy effects on movement-related gating are modulated by continuous theta-burst stimulation of the dorsolateral prefrontal cortex and primary somatosensory cortex. Experimental Brain Research, 233, 927-936. doi:10.1007/s00221-014-4168-6

Brozzoli, C., Pavani, F., Urquizar, C., Cardinali, L., \& Farne, A. (2009). Grasping actions remap peripersonal space. NeuroReport, 20, 913 917. doi:10.1097/WNR.0b013e32832c0b9b

Buckingham, G., Carey, D. P., Colino, F. L., DeGrosbois, J., \& Binsted, G. (2010). Gating of vibrotactile detection during visually guided bimanual reaches. Experimental Brain Research, 201(3), 411-419. doi: $10.1007 / \mathrm{s} 00221-009-2050-8$

Bultitude, J. H., Juravle, G., \& Spence, C. (2016). Tactile gap detection deteriorates during bimanual symmetrical movements under mirror visual feedback. PLoS ONE, 11(1), e0146077. doi:10.1371/journal. pone. 0146077

Burr, D. C., \& Morrone, M. C. (2011). Spatiotopic coding and remapping in humans. Philosophical Transactions of the Royal Society of London, Series B: Biological Sciences, 366(1564), 504-515. doi:10.1098/rstb.2010.0244

Burton, H. (2001). Cerebral cortical regions devoted to the somatosensory system: Results from brain imaging studies in humans. In R. J. Nelson (Ed.), The somatosensory system: Deciphering the brain's own body image (pp. 27-72). New York: CRC Press.
Burton, H., \& Sinclair, R. J. (2000). Attending to and remembering tactile stimuli: A review of brain imaging data and single-neuron responses. Journal of Cinical Neurophysiology, 17(6), 575-591.

Cameron, O. G. (2002). Visceral sensory neuroscience. Oxford: Oxford University Press.

Cardoso-Leite, P., Mamassian, P., Schütz-Bosbach, S., \& Waszak, F. (2010). A new look at sensory attenuation: Action-effect anticipation affects sensitivity, not response bias. Psychological Science, 21(12), 1740-1745. doi:10.1177/0956797610389187

Carlson, N. R. (2009). Physiology of behavior. New York: Allyn \& Bacon.

Chan, M., Estève, D., Fourniols, J.-Y., Escriba, C., \& Campo, E. (2012). Smart wearable systems: Current status and future challenges. Artificial Intelligence in Medicine, 56(3), 137-156. doi:10.1016/j. artmed.2012.09.003

Chapman, C. E., \& Beauchamp, E. (2006). Differential controls over tactile detection in humans by motor commands and peripheral reafference. Journal of Neurophysiology, 96(3), 1664-1675. doi:10.1152/jn.00214.2006

Chapman, C. E., Bushnell, M. C., Miron, D., Duncan, G. H., \& Lund, J. P. (1987). Sensory perception during movement in man. Experimental Brain Research, 68, 516-524.

Chapman, C. E., \& Tremblay, F. (2015). Tactile suppression. Scholarpedia, 10(3), 7953. doi:10.4249/scholarpedia.7953

Coen-Cagli, R., Kohn, A., \& Schwartz, O. (2015). Flexible gating of contextual influences in natural vision. Nature Neuroscience, 18(11), 1648-1655. doi:10.1038/nn.4128

Colino, F. L., \& Binsted, G. (2014). Pantomime grasping attenuates tactile sensitivity of the moving limb. Paper presented at the Society for Neuroscience annual meeting, Washington, DC.

Colino, F. L., \& Binsted, G. (2016). Time course of tactile gating in a reach-to-grasp and lift task. Journal of Motor Behaviour. doi:10.1080/00222895.2015.1113917

Colino, F. L., Buckingham, G., Cheng, D. T., van Donkelaar, P., \& Binsted, G. (2014). Tactile gating in a reaching and grasping task. Physiological Reports, 2, e00267. doi:10.1002/phy2.267

Colino, F. L., Lee, J.-H., \& Binsted, G. (2016). Availability of vision and tactile gating: vision enhances tactile sensitivity. Experimental Brain Research. doi:10.1007/s00221-016-4785-3

Collins, D. F., Cameron, T., Gillard, D. M., \& Prochazka, A. (1998). Muscular sense is attenuated when humans move. Journal of Physiology, 508(1998), 635-643. doi:10.1111/j.14697793.1998.00635.x

Collins, T., Heed, T., \& Röder, B. (2010). Visual target selection and motor planning define attentional enhancement at perceptual processing stages. Frontiers in Human Neuroscience, 4(March), 14. doi:10.3389/neuro.09.014.2010

Conte, A., Rocchi, L., Nardella, A., Dispenza, S., Scontrini, A., Khan, N., \& Berardelli, A. (2012). Theta-burst stimulation-induced plasticity over primary somatosensory cortex changes somatosensory temporal discrimination in healthy humans. PLoS ONE, 7(3), 1-8. doi:10.1371/journal.pone.0032979

Craig, A. D. (2002). How do you feel? interoception: The sense of the physiological condition of the body. Nature Reviews Neuroscience, 3(8), 655-666. doi:10.1038/nrn894

Crossman, E. R. F. W. (1959). A theory of the aquisition of speed-skill. Ergonomics, 2(2), 153-166. doi:10.1080/00140135908930419

Cybulska-Klosowicz, A., Meftah, E.-M., Raby, M., Lemieux, M.-L., \& Chapman, C. E. (2011). A critical speed for gating of tactile detection during voluntary movement. Experimental Brain Research, 210(2), 291-301. doi:10.1007/s00221-011-2632-0

de Graaf, C. (2012). Texture and satiation: the role of oro-sensory exposure time. Physiology \& Behavior, 107(4), 496-501. doi:10.1016/j. physbeh.2012.05.008

de Lafuente, V., \& Romo, R. (2005). Neuronal correlates of subjective sensory experience. Nature Neuroscience, 8(12), 1698-1703. doi: $10.1038 / \mathrm{nn} 1587$ 
Debats, N. B., Rohde, M., Glowania, C., \& Ernst, M. O. (2016). The influence of motor task on tactile suppression during action. In Proceedings of the International Conference on Human Haptic Sensing and Touch Enabled Computer Applications (Vol. 9744, pp. 158-167). London, UK: Springer International. doi:10.1007 1978-3-319-42321-0 15

Deiber, M. P., Ibanez, V., Honda, M., Sadato, N., Raman, R., \& Hallett, M. (1998). Cerebral processes related to visuomotor imagery and generation of simple finger movements studied with positron emission tomography. NeuroImage, 7(7), 73-85. doi:10.1006 /nimg.1997.0314

Desantis, A., Weiss, C., Schütz-Bosbach, S., \& Waszak, F. (2012). Believing and perceiving: Authorship belief modulates sensory attenuation. PLoS ONE, 7(5), 3-7. doi:10.1371/journal.pone.0037959

Desmurget, M., \& Grafton, S. (2000). Forward modeling allows feedback control for fast reaching movements. Trends in Cognitive Sciences, 4(11), 423-431. doi:10.1016/S1364-6613(00)01537-0

Deubel, H., \& Schneider, W. (1996). Saccade target selection and object recognition: Evidence for a common attentional mechanism. Vision Research, 36, 1827-1837. doi:10.1016/0042-6989(95)00294-4

Doya, K. (1999). What are the computations of the cerebellum, the basal ganglia and the cerebral cortex? Neural Networks, 12(7/8), 961974. doi:10.1016/S0893-6080(99)00046-5

Doya, K. (2000). Complementary roles of basal ganglia and cerebellum in learning and motor control. Current Opinion in Neurobiology, 10, 732-739. doi:10.1016/S0959-4388(00)00153-7

Dugas, C., \& Smith, A. M. (1992). Responses of cerebellar Purkinje cells to slip of a hand-held object. Journal of Neurophysiology, 67, 483-495.

Farnè, A., Brozzoli, C., Senna, I., \& Pavani, F. (2015). Driving handobjects interactions in depth by anticipated weighting of visuotactile processing. In Proceedings of the 16th International Multisensory Research Forum (p. 7). Pisa, Italy.

Fleming, S. M., Maniscalco, B., Ko, Y., Amendi, N., Ro, T., \& Lau, H. (2015). Action-specific disruption of perceptual confidence. Psychological Science, 26(1), 89-98. doi:10.1177 /0956797614557697

Friston, K. (2005). A theory of cortical responses. Philosophical Transactions of the Royal Society of London B: Biological Sciences, 360(1456), 815-836. doi:10.1098/rstb.2005.1622

Friston, K., Mattout, J., \& Kilner, J. (2011). Action understanding and active inference. Biological Cybernetics, 104(1/2), 137-160. doi:10.1007/s00422-011-0424-z

Gallace, A., \& Spence, C. (2014). In touch with the future: The sense of touch from cognitive neuroscience to virtual reality. Oxford: Oxford University Press.

Gallace, A., Zeeden, S., Röder, B., \& Spence, C. (2010). Lost in the move? Secondary task performance impairs tactile change detection on the body. Consciousness and Cognition, 19(1), 215-229. doi:10.1016/j.concog.2009.07.003

Gazzaniga, M. S., Ivry, R., \& Mangun, G. R. (2002). Cognitive neuroscience: The biology of the mind (2nd ed.). New York: Norton.

Gentsch, A., Panagiotopoulou, E., \& Fotopoulou, A. (2015). Active interpersonal touch gives rise to the social softness illusion. Current Biology, 25(18), 1-6. doi:10.1016/j.cub.2015.07.049

Gentsch, A., Schütz-Bosbach, S., Endrass, T., \& Kathmann, N. (2012). Dysfunctional forward model mechanisms and aberrant sense of agency in obsessive-compulsive disorder. Biological Psychiatry, 71(7), 652-659. doi:10.1016/j.biopsych.2011.12.022

Gerardin, E., Sirigu, A., Lehericy, S., Poline, J.-B., Gaymard, B., Marsault, C., \& Le Bihan, G. (2000). Partially overlapping neural networks for real and imagined hand movements. Cerebral Cortex, 10(11), 1093-1104. doi:10.1093/cercor/10.11.1093

Gomez, R., \& Harrison, A. (2014). Beyond wearables: Experiences and trends in design of portable medical devices. In A. Marcus (Ed.), Design, user experience, and usability (pp. 261-272). Cham: Springer International.
Goodale, M. A., Jakobson, L. S., \& Keillor, J. M. (1994). Differences in the visual control of pantomimed and natural grasping movements. Neuropsychologia, 32(10), 1159-1178.

Green, B. G., \& Nachtigal, D. (2012). Somatosensory factors in taste perception: Effects of active tasting and solution temperature. Physiology and Behavior, 107(4), 488-495. doi:10.1016/j. physbeh.2012.05.010

Haggard, P., \& Whitford, B. (2004). Supplementary motor area provides an efferent signal for sensory suppression. Cognitive Brain Research, 19, 52-58. doi:10.1016/j.cogbrainres.2003.10.018

Harris, L. R., \& Lieberman, L. (1996). Auditory stimulus detection is not suppressed during saccadic eye movements. Perception, 25, 9991004. doi:10.1068/p250999

Helmchen, C., Mohr, C., Erdmann, C., Binkofski, F., \& Büchel, C. (2006). Neural activity related to self- versus externally generated painful stimuli reveals distinct differences in the lateral pain system in a parametric fMRI study. Human Brain Mapping, 27(9), 755-765. doi:10.1002/hbm.20217

Hughes, G. (2015). ERP and behavioral evidence of increased sensory attenuation for fear-related action outcomes. Biological Psychology, 111, 8-13. doi:10.1016/j.biopsycho.2015.08.002

Humphries, A. K., \& Cioe, J. (2009). Reconsidering the refractory period: An exploratory study of women's post-orgasmic experiences. Canadian Journal of Human Sexuality, 18(3), 127-135.

Jeannerod, M., \& Frak, V. (1999). Mental imaging of motor activity in humans. Current Opinion in Neurobiology, 9(6), 735-739. doi:10.1016/S0959-4388(99)00038-0

Jordan, M. I., \& Rumelhart, D. E. (1992). Forward models: Supervised learning with a distal teacher. Cognitive Science, 16(3), 307-354. doi:10.1016/0364-0213(92)90036-T

Juravle, G. (2012). Moving \& feeling. The modulation of tactile perception during goal-directed movements: Evidence from reaching, grasping, catching, \& throwing (Doctoral thesis, University of Oxford, UK).

Juravle, G. (2015). Compression and suppression as instances of a similar mechanism affecting tactile perception during movement. Frontiers in Human Neuroscience, 9(April), 1-4. doi:10.3389 /fnhum.2015.00217

Juravle, G., \& Deubel, H. (2009). Action preparation enhances the processing of tactile targets. Experimental Brain Research, 198(2), 301-311. doi:10.1007/s00221-009-1819-0

Juravle, G., Deubel, H., \& Spence, C. (2011). Attention and suppression affect tactile perception in reach-to-grasp movements. Acta Psychologica, 138(2), 302-310. doi:10.1016/j.actpsy.2011.08.001

Juravle, G., Deubel, H., Tan, H. Z., \& Spence, C. (2010). Changes in tactile sensitivity over the time-course of a goal-directed movement. Behavioural Brain Research, 208, 391-401. doi:10.1016/j.bbr.2009.12.009

Juravle, G., Heed, T., Spence, C., \& Röder, B. (2016). Neural correlates of tactile perception during pre-, peri-, and post-movement. Experimental Brain Research, 234(5), 1293-1305. doi:10.1007 /s00221-016-4589-5

Juravle, G., McGlone, F., \& Spence, C. (2013). Context-dependent changes in tactile perception during movement execution. Frontiers in Psychology, 4, 913. doi:10.3389/fpsyg.2013.00913

Juravle, G., \& Spence, C. (2011). Juggling reveals a decisional component to tactile suppression. Experimental Brain Research, 213, 8797. doi:10.1007/s00221-011-2780-2

Juravle, G., \& Spence, C. (2012). Perceptual and decisional attenuation of tactile perception during the preparation of self- versus externallygenerated movements. Experimental Brain Research, 223(1), 109120. doi:10.1007/s00221-012-3245-y

Juravle, G., \& Spence, C. (2015). Speed of reaction to sensory stimulation is enhanced during movement. Acta Psychologica, 161, 154-161. doi:10.1016/j.actpsy.2015.09.002 
Kandel, E., Schwartz, J., \& Jessell, T. (2000). Principles of neural science (4th ed.). New York: McGraw-Hill.

Kawato, M. (1999). Internal models for motor control and trajectory planning. Current Opinion in Neurobiology, 9(6), 718-727. doi:10.1016/S0959-4388(99)00028-8

Kida, T., Nishihira, Y., Wasaka, T., Sakajiri, Y., \& Tazoe, T. (2004). Differential modulation of the short- and long-latency somatosensory evoked potentials in a forewarned reaction time task. Clinical Neurophysiology, 115(10), 2223-2230. doi:10.1016/j. clinph.2004.04.017

Kida, T., Wasaka, T., Nakata, H., Akatsuka, K., \& Kakigi, R. (2006). Centrifugal regulation of a task-relevant somatosensory signal triggering voluntary movement without a preceding warning signal. Experimental Brain Research, 173(4), 733-741. doi:10.1007 /s00221-006-0448-0

Kilner, J., Hamilton, A. F. D. C., \& Blakemore, S.-J. (2007). Interference effect of observed human movement on action is due to velocity profile of biological motion. Social Neuroscience, 2(3/4), 158166. doi:10.1080/17470910701428190

Kilner, J. M., Paulignan, Y., \& Blakemore, S.-J. (2003). An interference effect of observed biological movement on action. Current Biology, 13, 522-525. doi:10.1016/S0960-9822(03)00165-9

Klatzky, R. L., Lederman, S. J., \& Metzger, V. A. (1985). Identifying objects by touch: An "expert system.". Perception \& Psychophysics, 37, 299-302. doi:10.3758/BF03211351

Kühn, S., Nenchev, I., Haggard, P., Brass, M., Gallinat, J., \& Voss, M. (2011). Whodunnit? Electrophysiological correlates of agency judgements. PLOS ONE, 6(12), e28657. doi:10.1371/journal. pone. 0028657

Lederman, S. J., \& Klatzky, R. L. (2009). Haptic perception: A tutorial. Attention, Perception \& Psychophysics, 71(7), 1439-1459. doi:10.3758/APP.71.7.1439

Lee, R. G., \& White, D. G. (1974). Modification of the human somatosensory evoked response during voluntary movement. Electroencephalography and Cinical Neurophysiology, 36, 53-62. doi:10.1016/0013-4694(74)90136-9

London, B. M., \& Miller, L. E. (2013). Responses of somatosensory Area 2 neurons to actively and passively generated limb movements. Journal of Neurophysiology, 109(6), 1505-1513. doi:10.1152 jjn.00372.2012

Lu, H., Mcmanus, J. M., Cullins, M. J., \& Chiel, H. J. (2015). Preparing the periphery for a subsequent behavior: Motor neuronal activity during biting generates little force but prepares a retractor muscle to generate larger forces during swallowing in aplysia. Journal of Neuroscience, 35(12), 5051-5066. doi:10.1523 /JNEUROSCI.0614-14.2015

Macerollo, A., Chen, J. C., Pareés, I., Kassavetis, P., Kilner, J. M., \& Edwards, M. J. (2015). Sensory attenuation assessed by sensory evoked potentials in functional movement disorders. PLOS ONE, 10(6), 1-6. doi:10.1371/journal.pone.0129507

Manson, G., Wong, J., \& Tremblay, L. (2012). Auditory gating during visually-guided action? Seeing and Perceiving, 25, 106-106. doi:10.1163/187847612X647388

Maslovat, D., Chua, R., \& Hodges, N. J. (2013). When unintended movements "leak" out: A startling acoustic stimulus can elicit a prepared response during motor imagery and action observation. Neuropsychologia, 51(5), 838-844. doi:10.1016/j. neuropsychologia.2013.01.016

Masters, W. H., \& Johnson, V. E. (1966). Human sexual response. Boston: Little, Brown.

McGlone, F., Olausson, H., Boyle, J. A., Jones-Gotman, M., Dancer, C., Guest, S., \& Essick, G. (2012). Touching and feeling: Differences in pleasant touch processing between glabrous and hairy skin in humans. European Journal of Neuroscience, 35(11), 1782-1788. doi:10.1111/j.1460-9568.2012.08092.x
McGlone, F., \& Spence, C. (2010). Editorial: The cutaneous senses: Touch, temperature, pain/itch, and pleasure. Neuroscience \& Biobehavioral Reviews, 34, 145-147.

McGlone, F., Vallbo, A. B., Olausson, H., Loken, L., \& Wessberg, J. (2007). Discriminative touch and emotional touch. Canadian Journal of Experimental Psychology, 61(3), 173-183. doi:10.1037 /cjep2007019

McGlone, F., Wessberg, J., \& Olausson, H. (2014). Discriminative and affective touch: Sensing and feeling. Neuron, 82(4), 737-755. doi:10.1016/j.neuron.2014.05.001

Miall, R. C., \& Wolpert, D. M. (1996). Forward models for physiological motor control. Neural Networks, 9(8), 1265-1279. doi:10.1016 /S0893-6080(96)00035-4

Montoya, P., \& Sitges, C. (2006). Affective modulation of somatosensory-evoked potentials elicited by tactile stimulation. Brain Research, 1068(1), 205-212. doi:10.1016/j. brainres.2005.11.019

Morrone, M. C., Ross, J., \& Burr, D. (2005). Saccadic eye movements cause compression of time as well as space. Nature Neuroscience, 8(7), 950-954. doi:10.1038/nn1488

Mouchnino, L., Fontan, A., Tandonnet, C., Perrier, J., Saradjian, A., Blouin, J., \& Simoneau, M. (2015). Facilitation of cutaneous inputs during the planning phase of gait initiation. Journal of Neurophysiology, 114(1), 301-308. doi:10.1152/jn.00668.2014

Nakata, H., Inui, K., Wasaka, T., Nishihira, Y., \& Kakigi, R. (2003). Mechanisms of differences in gating effects on short-and long-latency somatosensory evoked potentials relating to movement. Brain Topography, 15(4), 211-222. doi:10.1023/A:1023908707851

Nakata, H., Sakamoto, K., Yumoto, M., \& Kakigi, R. (2011). The relationship in gating effects between short-latency and longlatency somatosensory-evoked potentials. Neuroreport, 22(18), 1000-1004. doi:10.1097/WNR.0b013e32834dc296

Nelson, R. J. (1996). Interactions between motor commands and somatic perception in sensorimotor cortex. Current Opinion in Neurobiology, 6, 801-810. doi:10.1016/S0959-4388(96)80031-6

Palmer, C. E., Davare, M., \& Kilner, J. M. (2016). Physiological and perceptual sensory attenuation have different underlying neurophysiological correlates. Journal of Neuroscience 36(42), 10803-10812

Pareés, I., Brown, H., Nuruki, A., Adams, R. A., Davare, M., Bhatia, K. P., \& Edwards, M. J. (2014). Loss of sensory attenuation in patients with functional (psychogenic) movement disorders. Brain, 137, 2916-2921. doi:10.1093/brain/awu237

Parkinson, A., Plukaard, S., Pears, S. L., Newport, R., Dijkerman, C., \& Jackson, S. R. (2011). Modulation of somatosensory perception by motor intention. Cognitive Neuroscience, 2(1), 47-56. doi:10.1080 $/ 17588928.2010 .525627$

Pezzulo, G., Rigoli, F., \& Friston, K. (2015). Active Inference, homeostatic regulation and adaptive behavioural control. Progress in Neurobiology, 134, 1-19. doi:10.1016/j.pneurobio.2015.09.001

Pleger, B., Ruff, C. C., Blankenburg, F., Bestmann, S., Wiech, K., Stephan, K. E., \& Dolan, R. J. (2006). Neural coding of tactile decisions in the human prefrontal cortex. Journal of Neuroscience, 26(48), 12596-12601. doi:10.1523 /JNEUROSCI.4275-06.2006

Popovich, C., \& Staines, W. R. (2015). Acute aerobic exercise enhances attentional modulation of somatosensory event-related potentials during a tactile discrimination task. Behavioural Brain Research, 281, 267-275. doi:10.1016/j.bbr.2014.12.045

Rizzolatti, G., \& Craighero, L. (2010). Premotor theory of spatial attention. Retrieved from http://www.scholarpedia. org/article/Premotor_theory_of_attention

Rizzolatti, G., Riggio, L., \& Sheliga, B. (1994). Space and selective attention. In C. Umiltà \& M. Moscovitch (Eds.), Attention and performance $X V$ (pp. 231-265). Cambridge: MIT Press.

Rohde, M., Debats, N., \& Ernst, M. O. (2015). Stimulus predictability modulates perceived tactile intensity. In Proceedings 
of the 16th International Multisensory Research Forum (pp. 31-32). Pisa, Italy.

Romo, R., Hernandez, A., \& Zainos, A. (2004). Neuronal correlates of perceptual decision in ventral premotor cortex. Neuron, 41, 165173. doi:10.1016/S0896-6273(03)00817-1

Rorden, C., Greene, K., Sasine, G. M., \& Baylis, G. C. (2002). Enhanced tactile performance at the destination of an upcoming saccade. Current Biology, 12(16), 1429-1434. doi:10.1016/S0960-9822(02 )01039-4

Rosenberg-Katz, K., Jamshy, S., Singer, N., Podlipsky, I., Kipervasser, S., Andelman, F., \& Hendler, T. (2012). Enhanced functional synchronization of medial and lateral PFC underlies internally-guided action planning. Frontiers in Human Neuroscience, 6(April), 79. doi:10.3389/fnhum.2012.00079

Rossini, P. M., Babiloni, C., Babiloni, F., Ambrosini, A., Onorati, P., Carducci, F., \& Urbano, A. (1999). "Gating" of human shortlatency somatosensory evoked cortical responses during execution of movement. A high resolution electroencephalography study. Brain Research, 843(1/2), 161-170. doi:10.1016/S0006-8993(99 )01716-3

Rossini, P. M., Caramia, D., Bassetti, M. A., Pasqualetti, P., Tecchio, F., \& Bernardi, G. (1996). Somatosensory evoked potentials during the ideation and execution of individual finger movements. Muscle \& Nerve, 19(2), 191-202. doi:10.1002/(SICI)1097

Roussel, C., Hughes, G., \& Waszak, F. (2013). A preactivation account of sensory attenuation. Neuropsychologia, 51(5), 922-929. doi:10.1016/j.neuropsychologia.2013.02.005

Saradjian, A. H. (2015). Sensory modulation of movement, posture and locomotion. Neurophysiologie Clinique/Clinical Neurophysiology, 45(4), 255-267. doi:10.1016/j.neucli.2015.09.004

Saradjian, A. H., Tremblay, L., Perrier, J., Blouin, J., \& Mouchnino, L. (2013). Cortical facilitation of proprioceptive inputs related to gravitational balance constraints during step preparation. Journal of Neurophysiology, 110(2), 397-407. doi:10.1152/jn.00905.2012

Shergill, S. S., Bays, P. M., Frith, C. D., \& Wolpert, D. M. (2003). Two eyes for an eye: The neuroscience of force escalation. Science, 301(5630), 187. doi:10.1126/science.1085327

Shergill, S. S., White, T. P., Joyce, D. W., Bays, P. M., Wolpert, D. M., \& Frith, C. D. (2013). Modulation of somatosensory processing by action. NeuroImage, 70, 356-362. doi:10.1016/j. neuroimage.2012.12.043

Sober, S. J., \& Sabes, P. N. (2003). Multisensory integration during motor planning. The Journal of Neuroscience, 23(18), 6982-6992. doi: citeulike-article-id:409345

Sowman, P. F., Brinkworth, R. S. A., \& Türker, K. S. (2010). Threshold for detection of incisal forces is increased by jaw movement. Journal of Dental Research, 89(4), 395-399. doi:10.1177 /0022034510363101

Timm, J., Sanmiguel, I., Keil, J., Schröger, E., \& Schönwiesner, M. (2014). Motor intention determines sensory attenuation of brain responses to self-initiated sounds. Journal of Cognitive Neuroscience, 26(7), 1481-1489. doi:10.1162/jocn_a_00552

Todorov, E. (2004). Optimality principles in sensorimotor control. Nature Neuroscience, 7(9), 907-915. doi:10.1038/nn1309

Tomassini, A., Gori, M., Baud-Bovy, G., Sandini, G., \& Morrone, M. C. (2014). Motor commands induce time compression for tactile stimuli. Journal of Neuroscience, 34(27), 9164-9172. doi:10.1523 /JNEUROSCI.2782-13.2014

Tremblay, L., \& Nguyen, T. (2010). Real-time decreased sensitivity to an audio-visual illusion during goal-directed reaching. PLOS ONE, 5(1), 2-5. doi:10.1371/journal.pone.0008952

Vaitl, D., Mittelstaedt, H., \& Baisch, F. (1997). Shifts in blood volume alter the perception of posture. International Journal of Psychophysiology, 27(2), 99-105. doi:10.1016/S0167-8760(97 )00053-6
Vaitl, D., Mittelstaedt, H., Saborowski, R., Stark, R., \& Baisch, F. (2002). Shifts in blood volume alter the perception of posture: Further evidence for somatic graviception. International Journal of Psychophysiology, 44(1), 1-11. doi:10.1016/S0167-8760(01 )00184-2

Van Doorn, G. H., Richardson, B. L., Wuillemin, D. B., \& Symmons, M. A. (2005). Modification of magnitude estimations in thermotactile perception during self-generated and externally generated movements. Perception, 34(2), 231236. doi:10.1068/p5367

Van Doorn, G., Paton, B., Howell, J., \& Hohwy, J. (2015). Attenuated self-tickle sensation even under trajectory perturbation. Consciousness and Cognition, 36, 147-153. doi:10.1016/j. concog.2015.06.016

van Ede, F., van Doren, T. I., Damhuis, J., de Lange, F. P., \& Maris, E. (2015). Movement preparation improves touch perception without awareness. Cognition, 137, 189-195. doi:10.1016/j. cognition.2015.01.009

Van Hulle, L., Juravle, G., Spence, C., Crombez, G., \& Van Damme, S. (2013). Attention modulates sensory suppression during back movements. Consciousness and Cognition, 22(2), 420-429. doi:10.1016 /j.concog.2013.01.011

Vastano, R., Inuggi, A., Vargas, C. D., Baud-Bovy, G., Jacono, M., \& Pozzo, T. (2016). Tactile perception during action observation. Experimental Brain Research, 234(9), 2585-2594. doi:10.1007 /s00221-016-4663-Z

Voisin, J. I. A., Rodrigues, E. C., Hétu, S., Jackson, P. L., Vargas, C. D., Malouin, F., \& Mercier, C. (2011). Modulation of the response to a somatosensory stimulation of the hand during the observation of manual actions. Experimental Brain Research, 208(1), 11-19. doi:10.1007/s00221-010-2448-3

Voss, M., Bays, P. M., Rothwell, J. C., \& Wolpert, D. M. (2007). An improvement in perception of self-generated tactile stimuli following theta-burst stimulation of primary motor cortex. Neuropsychologia, 45, 2712-2717. doi:10.1016/j. neuropsychologia.2007.04.008

Voudouris, D., \& Fiehler, K. (2015). Tactile suppression to visual and proprioceptive targets. In Proceedings of the 16th International Multisensory Research Forum (p. 55). Pisa, Italy.

Walsh, L. D., Taylor, J. L., \& Gandevia, S. C. (2011). Overestimation of force during matching of externally generated forces. Journal of Physiology, 589(3), 547-557. doi:10.1113/jphysiol.2010.198689

Wasaka, T., Kida, T., \& Kakigi, R. (2012). Modulation of somatosensory evoked potentials during force generation and relaxation. Experimental Brain Research, 219(2), 227-233. doi:10.1007 /s00221-012-3082-Z

Weiskrantz, L., Elliott, J., \& Darlington, C. (1971). Preliminary observations on tickling oneself. Nature, 230(5296), 598-599. doi:10.1038 /230598a0

Weiss, C., Herwig, A., \& Schütz-Bosbach, S. (2011). The self in social interactions: Sensory attenuation of auditory action effects is stronger in interactions with others. PLoS ONE, 6(7), e22723. doi:10.1371/journal.pone. 0022723

Williams, S. R., \& Chapman, C. E. (2000). Time course and magnitude of movement-related gating of tactile detection in humans: II. Effects of stimulus intensity. Journal of Neurophysiology, 84(2), 863-875.

Williams, S. R., \& Chapman, C. E. (2002). Time course and magnitude of movement-related gating of tactile detection in humans: III. Effect of motor tasks. Journal of Neurophysiology, 88(4), 1968-1979. doi:10.1152 /jn.00527.2001

Williams, S. R., Shenasa, J., \& Chapman, C. E. (1998). Time course and magnitude of movement-related gating of tactile detection in 
humans: I. importance of stimulus location. Journal of Neurophysiology, 79, 947-963.

Wise, S. P. (1985). The primate premotor cortex: Past, present, and preparatory. Annual Reviews Neuroscience, 8, 1-19. doi:10.1146 /annurev.ne.08.030185.000245

Witt, J. K., Taylor, J. E. T., Sugovic, M., \& Wixted, J. T. (2015). Signal detection measures cannot distinguish perceptual biases from response biases. Perception, 44, 289-300. doi:10.1068/p7908

Wolpert, D. M., Diedrichsen, J., \& Flanagan, J. R. (2011). Principles of sensorimotor learning. Nature Reviews Neuroscience, 12(12), 739751. doi:10.1038/nrn3112
Wolpert, D. M., \& Flanagan, J. R. (2001). Motor prediction. Current Biology, 11(18), R729-R723. doi:10.1016/S0960-9822(01)00432-8

Wolpert, D. M., Ghahramani, Z., \& Jordan, M. I. (1995). An internal model for sensoriomotor integration. Science, 269(5232), 1880 1882. doi:10.1126/science. 7569931

Ziat, M., Hayward, V., Chapman, C. E., Ernst, M. O., \& Lenay, C. (2010). Tactile suppression of displacement. Experimental Brain Research, 206(3), 299-310. doi:10.1007/s00221-010-2407-z 